\section{Grenzwert der Messabweichung}

C. Vidal ${ }^{1}$ und W.-R. Külpmann ${ }^{2}$

${ }^{1}$ Landeskriminalamt Niedersachsen, Dezernat 53 „Chemie“, Hannover, Deutschland

${ }^{2}$ Hannover, Deutschland

Synonym(e) Fehlergrenze

Englischer Begriff maximum permissible measurement error; maximum permissible error; limit of error
Definition Extremwert einer Messabweichung in Bezug auf einen bekannten Referenzwert, durch Spezifikation oder Vorschriften zugelassen für eine Messung, ein Messgerät oder ein Messsystem (BIPM et al. 2010). Für Anmerkungen s. Literatur.

\section{Literatur}

BIPM, IEC, IFCC, ILAC, ISO, IUPAC, IUPAP, OIML (2010) Internationales Wörterbuch der Metrologie (VIM). Deutsch-englische Fassung. ISO/IEC-Leitfaden 99:2007, 3. Aufl. Beuth-Verlag, Berlin 